\title{
COMPARATIVE STUDY FOR PERFORMANCE ANALYSIS OF ROUTING PROTOCOLS IN MOBILITY AND NON-MOBILITY SCENARIOS
}

\author{
Paresh Acharekar ${ }^{1}$, Dr. Saurabh Mehta ${ }^{2} \&$ Prof. Shraddha panbude ${ }^{3}$ \\ ${ }^{1}$ Student in Department of EXTC, Vidyalankar institute of Technology, Mumbai India, \\ $2 \& 3$ Department of EXTC,Vidyalankar institute of Technology, Mumbai India.
}

\begin{abstract}
A Mobile Ad-hoc Network (MANET) has a collection of numbers of wireless nodes which is each device in MANET having ability to free to move in any direction so that it is useful in all applications. In MANET nodes change position quite frequently, this means that we have need routing protocols that quickly adapts to topology changes. An ad-hoc network is self-organising and distributive in manner. The MANET is works as router so that linked with the other nearest devices. A mobile ad hoc network (MANET) is a wireless network follows the multiple hop routing instead of static network infra to provide network connectivity. Each device in a MANET is free to move independently in all direction freewaysand will therefore nodes change position in large networks all routing protocols. The routing protocols are needed for conveying information in Ad-hoc network there are various performance parameters to compare the Ad-hoc routing protocols.
\end{abstract}

My area of interest in this paper to analyze the different performance parameters Recent research has focused on simulation studies with mobility and non-mobility scenarios to investigate and improve routing protocols. we have simulate the all three routing protocols in mobility as well as non-mobility scenario with nodes up to 300 also plot the graphs throughput, Delay, PDR, Dropping Ratio, and average energy consumption by using Network Simulator version 2.34. ).

\section{KEYWORDS:}

Routing, MANET, DSDV, DSR, AODV, NS-2.

\section{INTRODUCTION:}

Wireless cellular systems have been in used since 1980s. These systems work with the support of supporting structure environment and having centralized access point. The mobile user connected as all the way which has centralized access point in prior one [1]. 
Emerging Trends in Electrical, Electronics \& Instrumentation Engineering: An international Journal (EEIEJ), Vol. 3, No. 1/2/3, August 2016

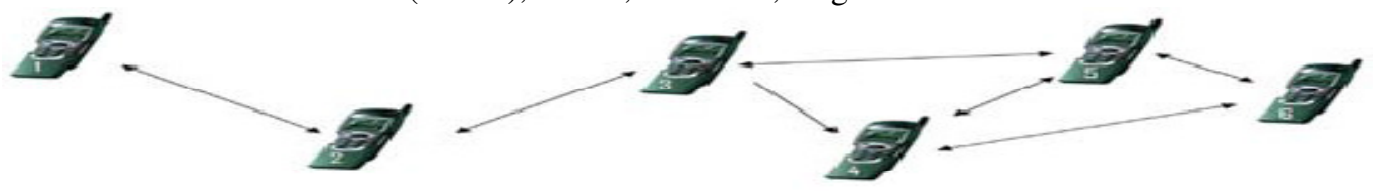

Figure.1 Mobile Ad-hoc Networks (MANET )[Ref:13]

A mobile ad hoc network (MANET) is a collection of wireless nodes. The MANET acts as Router which is moving independently and freely in the organized network which has number of host connected to them. As per fig 1 shown that the 6 mobile nodes which are connecting each other via ad-hoc network. Mobile node 1 is not within the transmission range of 4 If mobile node 1 wants to establish communication with node 4 , Node 3 which in the transmission range of node 2 and 4 forwards the packets so that node 1 and 4 are able to communicate each other successfully.The fixed network is different than MANET which is MANET technology is mobile [3]. Mobiles nodes are capability to send the packet during transmission.Routing is very important function in network whether the network is wired or wireless.

As per the mobility and Non-mobility characteristics are expected to have effective output of the routing protocols like DSR [4], AODV [1] \& DSDV [2].We try to find out the mobility and nonmobility survey taking three different scenarios and need to observe its use also impact to choose the right protocol.Routing protocols are classified into Table driven and On demand protocols. In Table driven protocols, the route is predecided in a routing table while sending packets from source to destination which is destination node obtained the sequence number. Examples are DSDV (Destination Sequence Distance Vector On demand protocol, when the packets sent from source to destination then no pre-modified path developed in routing table.

DSR (Distance Source Routing) \& AODV (Ad hoc On Demand Distance Vector) Protocol [6]. Further, AODV performed good compared with the other protocols.The DSR and AODV showing almost similar outputs as compared to DSDV.

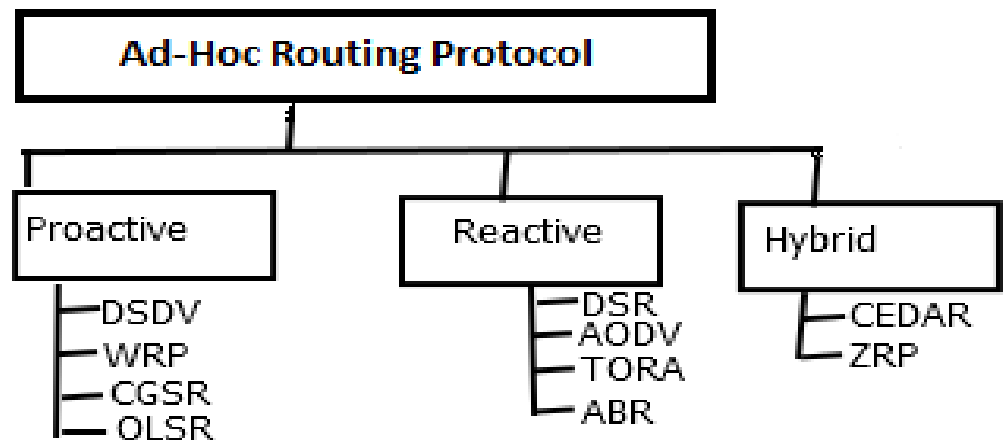

Figure.2 Classification of Routing Protocols[Ref:6] 
Emerging Trends in Electrical, Electronics \& Instrumentation Engineering: An international Journal

(EEIEJ), Vol. 3, No. 1/2/3, August 2016

\section{OVERVIEW OF ROUTING PROTOCOLS:}

\section{Ad Hoc On-demand Distance Vector Routing (AODV) :}

This is part of reactive routing protocol and interesting approach of this routing protocols has a nodes belong to active routes only need to share and maintain the routing information. AODV protocol determines new path information by destination sequence number generated by destination node. When destination received packet from source as RREQ then AODV creates the sequence number both the fields. The destination route send the RREP request to source for the new route developed on destination as per forwarding path RREQ[5].

\section{Dynamic Source Routing (DSR):}

When the packet received from source then route contains the entire information of source which sent to destination [4]. The source sends the packet to destination and initially sends the RREQ request to destination without affecting the network. The RREQ builds up a path whole the network and the RREP routes itself back to the source by traversing this path backward. Destination node should send the RREP packets to sender which contains address of both destination and source. The destination node has new route for the destination which receive RREQ packet responds by sending a RREP acknowledgement message[3].

\section{Destination Sequence Distance Vector (DSDV) :}

In DSDV, each node contains the next hop information. A sequence number generated by the destination node adds the each entry to prevent loops [3]. The dsdv requires the destination IP address for new sequence number also number of hops to reaching the destination node for every packet and last the sequence number of some information need to send it the packet to destination. In this routing protocol, formation of routing table and updates of table have preferred. The node re developed the tables as per received information, then generation of new sequence number, It is useful for small numbers of nodes [5].

\section{Related Work:}

The below tabular format follow the performance of my thesis over the different Routing Protocols

Table 2: Referred by Various Research Papers

\begin{tabular}{|c|c|c|c|c|}
\hline $\begin{array}{c}\text { Sr } \\
\text { No }\end{array}$ & References & Parameter & Previous Work analysis & Implementation of project \\
\hline 1 & $\begin{array}{c}\text { Akshai A et al.[12] } \\
\text { Sabinaet al.[7] }\end{array}$ & Nodes & $\begin{array}{c}\text { In mobility scenario, they } \\
\text { used up to 200 nodes and } \\
\text { performance of DSR is } \\
\text { worst with increases the } \\
\text { nodes }\end{array}$ & $\begin{array}{c}\text { We have used up to 300 } \\
\text { nodes so might be used Ex- } \\
\text { DSR with neural networks to } \\
\text { improve the throughput and } \\
\text { packet dropped parameters }\end{array}$ \\
\hline
\end{tabular}


Emerging Trends in Electrical, Electronics \& Instrumentation Engineering: An international Journal (EEIEJ), Vol. 3, No. 1/2/3, August 2016

\begin{tabular}{|c|c|c|c|c|}
\hline 2 & $\begin{array}{c}\text { Suman Kumariet al } \\
\text { [23], Kuljit Kauret al } \\
{[20]}\end{array}$ & Work & $\begin{array}{l}\text { AODV and DSR used on } \\
\text { On demand route } \\
\text { discovery phenomenon's } \\
\text { uses source routing and } \\
\text { route cache. }\end{array}$ & $\begin{array}{l}\text { Working on route discovery } \\
\text { and route maintenance } \\
\text { regarding the combination of } \\
\text { both in Modified-DSR } \\
\text { protocol. }\end{array}$ \\
\hline 3 & Zubair I et cl. [27] & $\begin{array}{l}\text { Performance } \\
\text { criteria }\end{array}$ & $\begin{array}{l}\text { As per simulation work, } \\
\text { AODV protocol better } \\
\text { performance in highest } \\
\text { number of nodes (up to } \\
\text { 200) }\end{array}$ & $\begin{array}{l}\text { As per simulation work DSR } \\
\text { perform low as high number } \\
\text { of nodes so I will improve } \\
\text { the performance of DSR } \\
\text { (similar to AODV) with } \\
\text { increasing number of nodes } \\
\text { (up to } 300 \text { )using Routing } \\
\text { Algorithm for Ex-DSR }\end{array}$ \\
\hline \multirow{2}{*}{4} & Preeti G et al.[17] & \multirow{2}{*}{$\begin{array}{l}\text { Packet } \\
\text { delivery } \\
\text { Ratio }\end{array}$} & \multirow{2}{*}{$\begin{array}{l}\text { As per graph the DSR } \\
\text { PDF performance decline } \\
\text { drastically (up to } 100 \\
\text { nodes) when the increased } \\
\text { no of node }\end{array}$} & \multirow{2}{*}{$\begin{array}{l}\text { we would improve PDF } \\
\text { performance of DSR when } \\
\text { increasing no of nodes ( after } \\
\text { 100) using the decision } \\
\text { algorithm }\end{array}$} \\
\hline & $\begin{array}{c}\text { Shashank dwivediet } \\
\text { al.[2] }\end{array}$ & & & \\
\hline 5 & $\begin{array}{l}\text { Parma Nand et al, } \\
\text { [16],VenetisKanakar } \\
\text { isetal. [3] }\end{array}$ & $\begin{array}{l}\text { Traffic and } \\
\text { Mobility }\end{array}$ & $\begin{array}{l}\text { AODV is DSR preferable } \\
\text { for Moderate mobility and } \\
\text { low traffic }\end{array}$ & $\begin{array}{l}\text { We have use the M-DSR } \\
\text { technology can improve the } \\
\text { high mobility and high traffic }\end{array}$ \\
\hline 6 & Gulati et al. [11] & Nodes & $\begin{array}{l}\text { A deeper simulation of } \\
\text { DSDV, AODV, DSR with } \\
\text { performance of all } \\
\text { protocol up to } 200 \text { mobile } \\
\text { nodes and AODV has } \\
\text { good one then DSR. }\end{array}$ & $\begin{array}{l}\text { AODV shown the awesome } \\
\text { experience in a network with } \\
\text { low mobility scenarios while } \\
\text { the AODV and DSR showing } \\
\text { better output as per their } \\
\text { characteristics in all mobility } \\
\text { scenario. }\end{array}$ \\
\hline 7 & $\begin{array}{c}\text { SamayveerS et. Al } \\
{[19]}\end{array}$ & $\begin{array}{l}\text { Performance } \\
\text { criteria }\end{array}$ & $\begin{array}{l}\text { The simulation analysis } \\
\text { carried out AODV and } \\
\text { DSR. In this paper that } \\
\text { the } \\
\text { The throughput and the } \\
\text { end-to end delay are used } \\
\text { for only } 50 \text { to } 100 \text { nodes. }\end{array}$ & $\begin{array}{l}\text { We have to use Modified- } \\
\text { DSR protocol Algorithm to } \\
\text { improve the few performance } \\
\text { parameters with } \\
\text { highlyutilized of nodes. }\end{array}$ \\
\hline 8 & $\begin{array}{c}\text { Dr Mudassar et al } \\
{[24]}\end{array}$ & $\begin{array}{l}\text { Protocols } \\
\text { used }\end{array}$ & $\begin{array}{l}\text { Performance comparison } \\
\text { of all three protocols and } \\
\text { among that basically } \\
\text { normally used protocol } \\
\text { which has characteristics } \\
\text { of protocol mainly focus } \\
\text { on routing for } \\
\text { better performance and } \\
\text { have little defense } \\
\text { capability against the } \\
\text { Variationof nodes. }\end{array}$ & $\begin{array}{l}\text { M-DSR preferable for } \\
\text { Moderate mobility and low } \\
\text { traffic as per AODV } \\
\text { protocol. }\end{array}$ \\
\hline
\end{tabular}


Emerging Trends in Electrical, Electronics \& Instrumentation Engineering: An international Journal (EEIEJ), Vol. 3, No. 1/2/3, August 2016

\begin{tabular}{|c|c|c|c|c|}
\hline 9 & $\begin{array}{l}\text { Hasein Issa Sigiuk et } \\
\text { al [8] } \\
\text { Dipankar S et al. [6] }\end{array}$ & $\begin{array}{l}\text { Performance } \\
\text { criteria }\end{array}$ & $\begin{array}{l}\text { In papertested the } \\
\text { comparison of both } \\
\text { scenario and DSR } \\
\text { protocol perform better } \\
\text { due to multiple path } \\
\text { registered kept the route } \\
\text { cache and provide } \\
\text { stability on the network of } \\
\text { variation of nodes DSDV } \\
\text { has low packet delivery } \\
\text { ratio and DSR having low } \\
\text { latency and energy } \\
\text { consumption }\end{array}$ & $\begin{array}{l}\text { We have used Ex-DSR } \\
\text { routing Algorithm to reach } \\
\text { the AODV performance } \\
\text { parameters and need to make } \\
\text { combination mobile sink and } \\
\text { static protocols which is best } \\
\text { in both scenario. }\end{array}$ \\
\hline 10 & $\begin{array}{c}\text { Rajeev Paulus et al } \\
{[14]}\end{array}$ & $\begin{array}{l}\text { Application } \\
\text { Metrics }\end{array}$ & $\begin{array}{l}\text { The authors showing that } \\
\text { DSR giving the less } \\
\text { dropping ratio than other } \\
\text { protocols but other } \\
\text { parameter are decreases } \\
\text { and also compare few } \\
\text { parameters. }\end{array}$ & $\begin{array}{l}\text { We have used Ex-DSR } \\
\text { routing Algorithm to reach } \\
\text { good performance of all } \\
\text { performance parameter. }\end{array}$ \\
\hline 11 & $\begin{array}{c}\text { Nitin Tyagi et al } \\
\text { [13] }\end{array}$ & congestion & $\begin{array}{l}\text { Worked on upto } 100 \\
\text { nodes in CBR traffic in } \\
\text { MANET }\end{array}$ & $\begin{array}{l}\text { We should be propose EX- } \\
\text { DSR protocol and implement } \\
\text { mobility as well as non- } \\
\text { mobility nodes constant } \\
\text { nodes upto } 300 \text { and we } \\
\text { would get some positive } \\
\text { results in performance } \\
\text { parameters. }\end{array}$ \\
\hline
\end{tabular}

This papers evaluates the three MANET routing protocols (DSDV, AODV and DSR) based on some quality of parameters like packet delivery ratio, Average energy consumption , Delay, throughput, dropping Ratio, packet received)

\section{Performance Metrics:}

In this paper, we are taking following performance parameters to compare the our survey paper routing protocol.

1. Delay :. The delay is calculated when the packet is generated and will send for transmission so that calculate the time interval will receiving application at the destination node.

2. Packet Delivery Ratio : The packet delivery ratio (PDR) is defined as the number of data packets delivered relative to the number of packets generated.

$$
\mathrm{PDR}=\text { packets generated } / \text { packets delivered }
$$

3. Throughput: The throughput of a connection between two paths which has determined by the number of bytes delivered per unit of time.

Throughput $=$ Total bytes received $/$ Total time 
Emerging Trends in Electrical, Electronics \& Instrumentation Engineering: An international Journal (EEIEJ), Vol. 3, No. 1/2/3, August 2016

4. Packet Dropping Ratio : Packet Delivery Ratio (PDR) is the ratio between source packets which has sent and same amount of packets received by a destination. Suppose packets are dropped calculate by this method.

5. Average Energy Consumption: Energy has been consumed when the packet has send in network.

\section{Network Simulator 2 :}

Network Simulator is a type of tool which uses to large nodes eg: ns-1, ns-2 and ns-3. All of them are discrete-event computer network simulators, primarily used in research.NS (Version 2) is an open source network simulation tool. It is basically use for wireless/ wire line network the protocol should use TCP,UDP.In this tool generate the NAM file as well as TAR file from .TCL file with different traffic and topologies. we can easily evaluated the graphs from .AWK file. The graphical based simulation tool exists in this NS2 which has easily showing so that we have used the NS2 [21].Basically NS2 OTCL, C++ scripts are used for separate control the paths. NS2 is good and easy to use to all types of protocols and network modules with different scenarios.It can runs various system like Linux 8.5, RHEL, cgywin, Fedora and Ubuntu. It uses the ad-hoc routing protocols like AODV, DSR, DSDV etc.

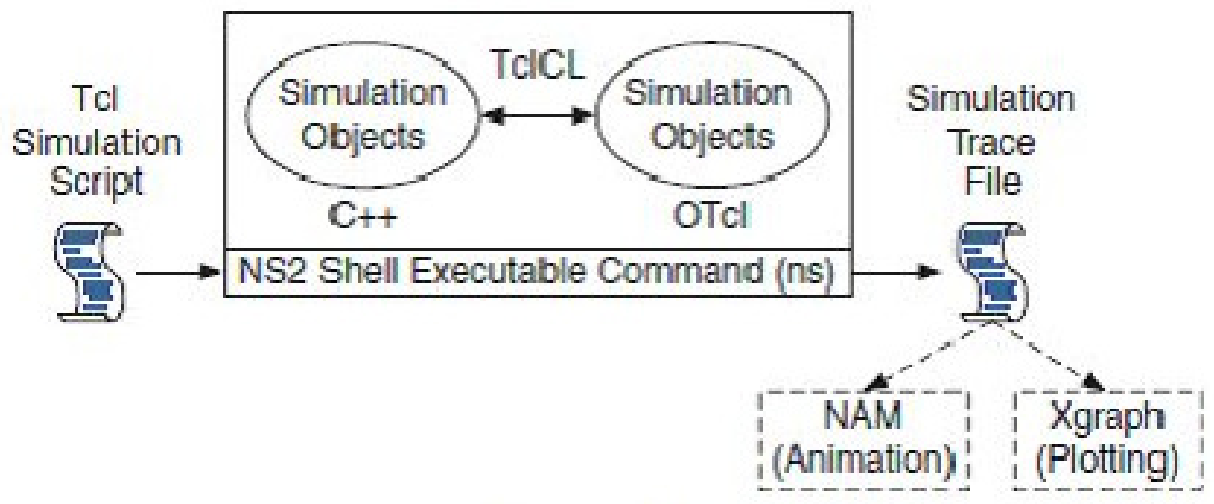

Figure 2. Basic Architecture of NS-2 Simulator

[Ref: NS-2 Network simulator http://www.isi.edu/nsnam/ns] 
Emerging Trends in Electrical, Electronics \& Instrumentation Engineering: An international Journal (EEIEJ), Vol. 3, No. 1/2/3, August 2016

Table 3. Comparison of Various Network Simulators

\begin{tabular}{|c|c|c|c|c|c|}
\hline Sr No & Parameter & OPNET & OMNeT++ & QualNet & NS2 \\
\hline 1 & License & Commercial & Open Source & Commercial & Open Source \\
\hline 2 & Support & $\begin{array}{l}\text { OPNET has } \\
\text { Integrated, GUI- } \\
\text { based debugging } \\
\text { and analysis for } \\
\text { the users. }\end{array}$ & $\begin{array}{l}\text { OMNeT++ has a } \\
\text { well- designed } \\
\text { simulation engine } \\
\text { and powerful GUI, } \\
\text { Includes Graphical } \\
\text { and command line } \\
\text { interfaces }\end{array}$ & $\begin{array}{l}\text { Qualnet has } \\
\text { complete } \\
\text { GUI provided, }\end{array}$ & $\begin{array}{l}\text { Ns-2 is most } \\
\text { popular } \\
\text { simulator for } \\
\text { academic } \\
\text { research } \\
\text { Graphical as } \\
\text { well as } \\
\text { command line } \\
\text { interface }\end{array}$ \\
\hline 3 & Platform & $\begin{array}{l}\text { C,C++,Opnet } \\
\text { modeler } \\
\text { software }\end{array}$ & Linux,mac-os,unix & Linux & $\begin{array}{l}\text { Unix,mac-OS } \\
\text { Microsoft } \\
\text { window } \\
\text { Cygwin }\end{array}$ \\
\hline 4 & $\begin{array}{l}\text { Specific } \\
\text { type }\end{array}$ & Castalia & Nsrlsensorsim & Viptos & SensorSim \\
\hline 5 & Mobility & Yes & No & No & Yes \\
\hline 6 & $\begin{array}{l}\text { Language } \\
\text { /Programmi } \\
\text { ng }\end{array}$ & $\begin{array}{l}\mathrm{C}++/ \text { Java object- } \\
\text { oriented }\end{array}$ & $\begin{array}{c}\mathrm{C}++/ \mathrm{C}++(\text { Highly } \\
\text { portable with } \\
\text { Windows,Linu } \mathrm{x} \text { and } \\
\text { Mac OSX }\end{array}$ & $\begin{array}{l}\text { Parsec C++/ } \\
\text { Parsec } \\
\text { (Simulation } \\
\text { language } \\
\text { Derived } \\
\text { from C) } \\
\end{array}$ & $\begin{array}{c}\mathrm{C}++/ \mathrm{OTCL} \\
\text { Object oriented } \\
\text { extension of } \mathrm{Tcl} \\
\text { and } \mathrm{C}++\end{array}$ \\
\hline
\end{tabular}

\section{Simulation Set Up:}

The simulations were performed use the Network Simulator 2 (NS-2.34) [7]. The mobility model using 'random waypoint model' in a rectangular field as $500 \mathrm{~m} \times 500 \mathrm{~m}$ with varying from 50 to 300 nodes. We have seen over this study thesis different number of nodes uses the mobility and non-mobility scenarios.CBR having good performance in mobility compared with VBR CBR traffic in our paper for improvement of DSR protocol for higher nodes and analyze the various performance parameters in CBR traffic also expected to show better result as per TCP traffic.The VBR traffic model couldn't supports in NS2 and if we are simulates the VBR results compared with CBR traffic then need to use the another simulator.

In Table 4, we have summarized the different parameters which has used for our experiments. 
Emerging Trends in Electrical, Electronics \& Instrumentation Engineering: An international Journal (EEIEJ), Vol. 3, No. 1/2/3, August 2016

Table 4 : Parameter values taken in simulation

\begin{tabular}{|c|c|}
\hline Parameter & Parameter Value \\
\hline Simulator & NS-2.34 \\
\hline Simulation grid size & M00x 500 \\
\hline MAC layer Protocol & Wireless channel \\
\hline Channel type & DSDV/ DSR/ AODV \\
\hline Routing protocols & 50.100 .150 .200 .250 .300 \\
\hline Mobile nodes & Omni directional antenna \\
\hline Antenna Type & Two Ray Ground \\
\hline Propagation Model & 500 bytes \\
\hline Packet size & CBR (UDP) \\
\hline Traffic & 100 sec \\
\hline Simulation time & Type LL \\
\hline Link Layer & Random Way point model \\
\hline Mobility Model & 10 m/s \\
\hline Maximum speed & \\
\hline
\end{tabular}

\section{Result and Discussion:}

In this Section, we have study the comparative performance of the three routing protocol. We have simulated of AODV, DSDV and DSR Ad-hoc routing protocols in simulation environment up to 300 mobile nodes as well as no mobile nodes. Graph show comparison between the three protocols with mobility and Non-mobility scenarios on the basis of the above-mentioned metrics.

\section{Graphs of Mobility Scenario in MANET:}

\section{Throughput:}

From the above figure 4 and table 5 Throughput has measured in bits per second so that amount of packets are send from source to destination which has amount of packets received by destination. AODV and DSR protocols gives good throughput after 100 nodes then DSDV protocol in mobility scenarios. In this parameter the AODV perform better which lead the more stable path from source to destination. 
Emerging Trends in Electrical, Electronics \& Instrumentation Engineering: An international Journal (EEIEJ), Vol. 3, No. 1/2/3, August 2016

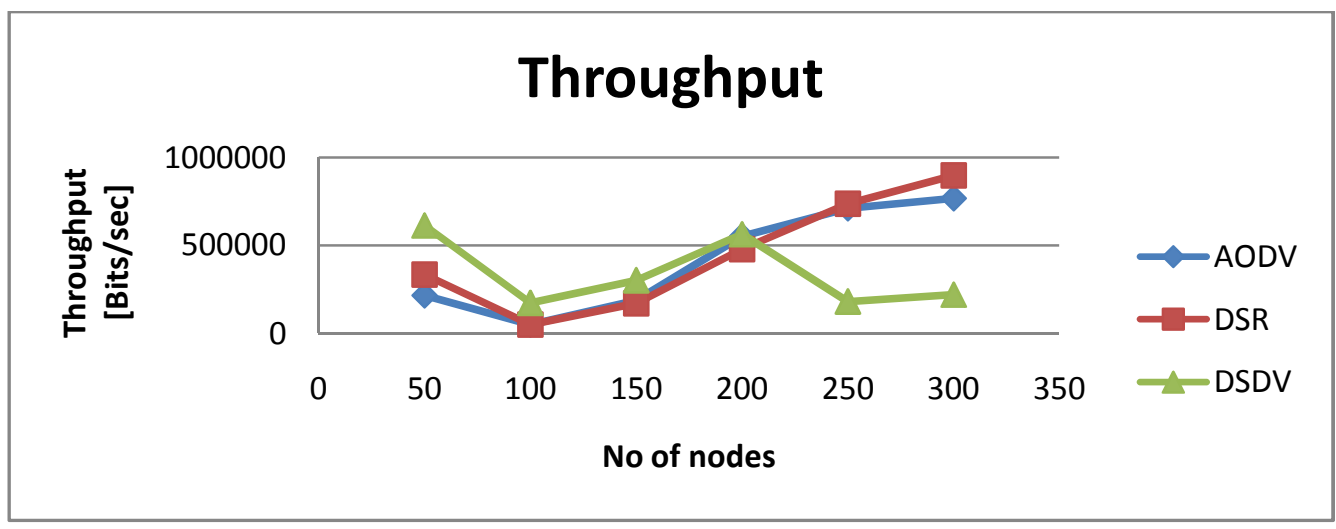

Figure: 4 Throughput vs Number of Nodes

Table 5 :Readings of Throughput vs No of nodes

\begin{tabular}{|c|c|c|c|}
\hline No of Nodes & AODV & DSR & DSDV \\
\hline 50 & 216500 & 334153 & 613065 \\
\hline 100 & 51008 & 51304.5 & 174442 \\
\hline 150 & 187842 & 171248 & 302579 \\
\hline 200 & 551278 & 479384 & 563308 \\
\hline 250 & 712032 & 736625 & 182306 \\
\hline 300 & 767654 & 897654 & 220914 \\
\hline
\end{tabular}

AODV and DSR has higher throughput than DSDV because of to avoid the formation of network loop and stable routes even if broken links. DSDV having a lower throughput for increasing numbers of nodes.

\section{Packet Delivery Ratio :}

In Figure 5 \&table 6 we have observed a slight advantage to AODV and DSR when the number of nodes has increased from 150 nodes in mobile networks.During route discovery and route maintenance scenario the few packets are loss in DSR and AODV that means the delay happened.DSDV is good in mobility scenario for PDR. so that AODV has low packet delivery fraction than DSR because of higher drop rates and DSDV having good performance in mobility scenario. 
Emerging Trends in Electrical, Electronics \& Instrumentation Engineering: An international Journal (EEIEJ), Vol. 3, No. 1/2/3, August 2016

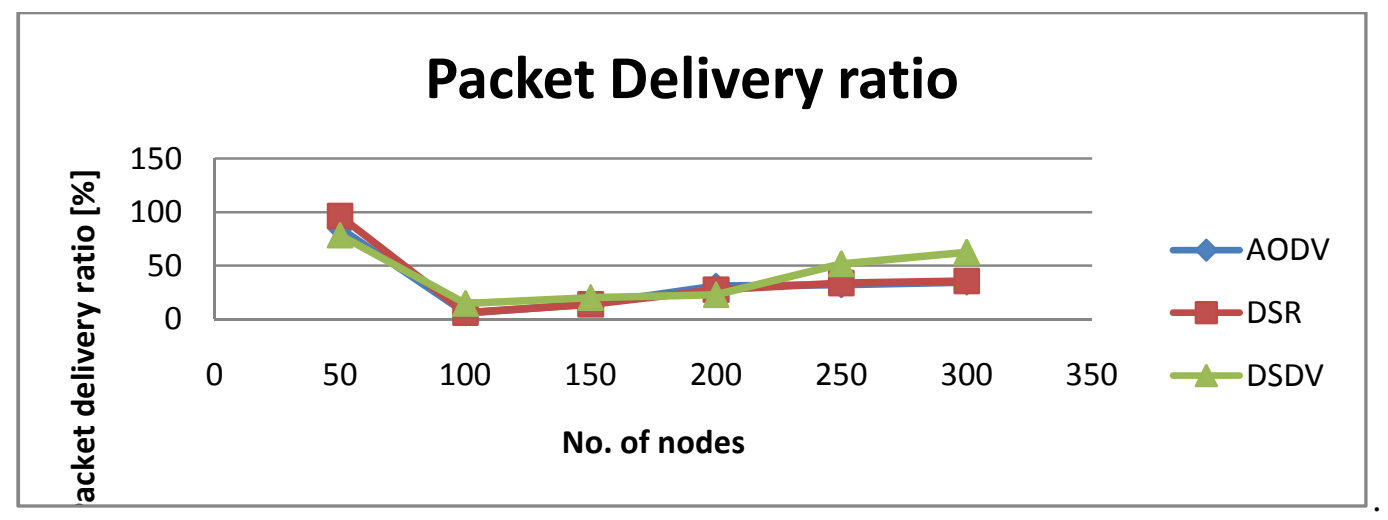

Figure: 5Packet Delivery Ratio vs Number of Nodes

Table 6 :Readings PDR vs No of nodes

\begin{tabular}{|c|c|c|c|}
\hline No of Nodes & AODV & DSR & DSDV \\
\hline 50 & 84.8372 & 96.3248 & 78.4119 \\
\hline 100 & 5.95087 & 6.16733 & 14.9198 \\
\hline 150 & 14.6446 & 13.7664 & 20.4225 \\
\hline 200 & 30.9199 & 27.4362 & 23.0888 \\
\hline 250 & 32.1339 & 33.6456 & 51.8034 \\
\hline 300 & 34.654 & 35.7654 & 62.6581 \\
\hline
\end{tabular}

\section{Delay:}

In Figure 6and table 7Due to route discovery process delay of DSR is increases from node 50 and up to 300 nodes it has $2.2 \mathrm{~ms}$ compared to AODV has average delay When the packet send Source to destination then DSDV maintain the route in routing table in that increased delay with formation of route.But in case of high traffic the DSR packets are get loss thus eliminating so that such situations DSR has relatively high delay than AODV in mobility scenario.

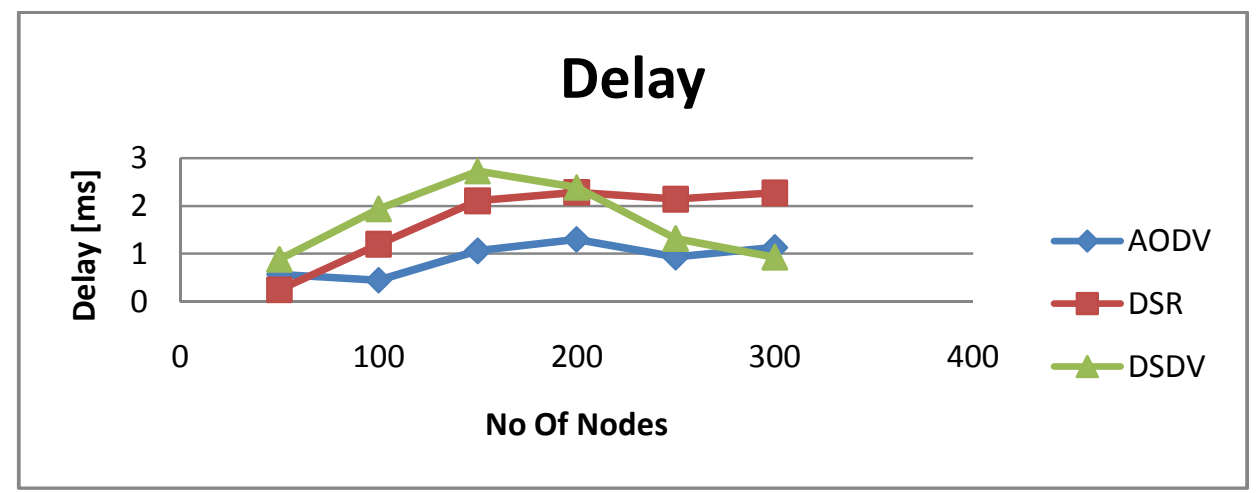

Figure: 6Delay vs Number of Nodes 
Emerging Trends in Electrical, Electronics \& Instrumentation Engineering: An international Journal (EEIEJ), Vol. 3, No. 1/2/3, August 2016

Table 7: Readings Delay vs No of nodes

\begin{tabular}{|c|c|c|c|}
\hline No of Nodes & AODV & DSR & DSDV \\
\hline 50 & 0.564031 & 0.243947 & 0.88559 \\
\hline 100 & 0.445553 & 1.19583 & 1.94105 \\
\hline 150 & 1.05896 & 2.10176 & 2.72909 \\
\hline 200 & 1.2968 & 2.27998 & 2.38812 \\
\hline 250 & 0.92875 & 2.13679 & 1.31997 \\
\hline 300 & 1.1275 & 2.26871 & 0.93151 \\
\hline
\end{tabular}

\section{Packet Dropping Ratio :}

In figure 9 mentioned that DSDV having constant packet dropping ratio to 300 nodes and when the increasing number of nodes (from 100 nodes) .Packet dropping ratio is very high in DSDV due to its charachrastics in route formation. When the nodes are increased further up to 300 , the packet loss for DSDV first increases and it would be decrease while AODV packet loss will little bit increase as the network size increases.

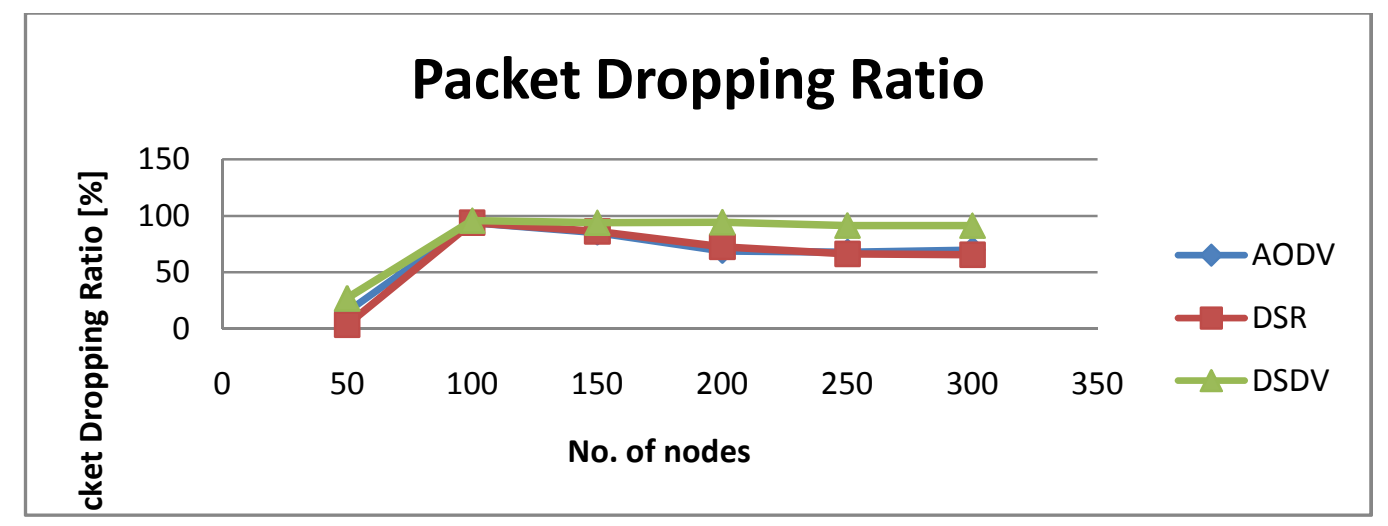

Figure: 9Packet Dropping Ratiovs Number of Nodes

Table 10 :Readings Packet Dropping Ratio vs No of nodes

\begin{tabular}{|c|c|c|c|}
\hline No of Nodes & AODV & DSR & DSDV \\
\hline 50 & 15.1628 & 3.67521 & 27.0342 \\
\hline 100 & 94.0491 & 93.8327 & 95.7602 \\
\hline 150 & 85.3554 & 86.2336 & 93.9476 \\
\hline 200 & 69.0801 & 72.5638 & 94.38 \\
\hline 250 & 67.8661 & 66.3544 & 91.4103 \\
\hline 300 & 69.8948 & 65.5467 & 91.3248 \\
\hline
\end{tabular}

\section{Average Energy Consumption :}

In AODV, when increases network size then increases the consumption of that protocol.The reactive protocol consumes high energy then proactive protocols. Due to collisions and 
Emerging Trends in Electrical, Electronics \& Instrumentation Engineering: An international Journal

(EEIEJ), Vol. 3, No. 1/2/3, August 2016

retransmission which cause the energy wastage in mobility scenario. DSDV performance is very low because maintaining the routing table entries and rebroadcast the packets when the breakage of links.

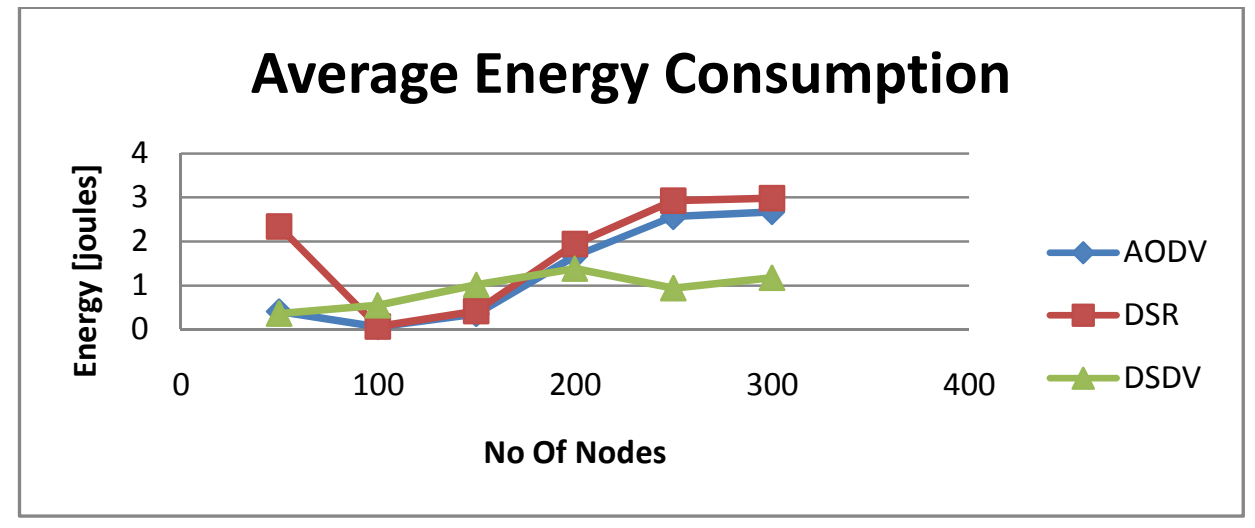

Figure: 10Average Energy Consumption vs Number of Nodes

Table 11 :Readings Average Energy Consumption vs No of nodes

\begin{tabular}{|c|c|c|c|}
\hline No of Nodes & AODV & DSR & DSDV \\
\hline 50 & 0.411349 & 2.34107 & 0.363086 \\
\hline 100 & 0.0644476 & 0.070608 & 0.549762 \\
\hline 150 & 0.36102 & 0.41766 & 1.01416 \\
\hline 200 & 1.67489 & 1.94307 & 1.38293 \\
\hline 250 & 2.56661 & 2.93104 & 0.939587 \\
\hline 300 & 2.67517 & 2.98713 & 1.17554 \\
\hline
\end{tabular}

\section{Graphs of Non-Mobility Scenario MANET:}

\section{Throughput}

From the above figure $11 \mathrm{AODV}$ and DSR protocols gives similar kind of throughput from origination of nodes. It's because of stale routing table entries.From the figures we observe that the performance of the AODV improves and is better than DSDV as the network grows.it is concluded that AODV and DSR performs very good and had a very heavy throughput in networks with relatively larger number of traffic sources. 
Emerging Trends in Electrical, Electronics \& Instrumentation Engineering: An international Journal (EEIEJ), Vol. 3, No. 1/2/3, August 2016

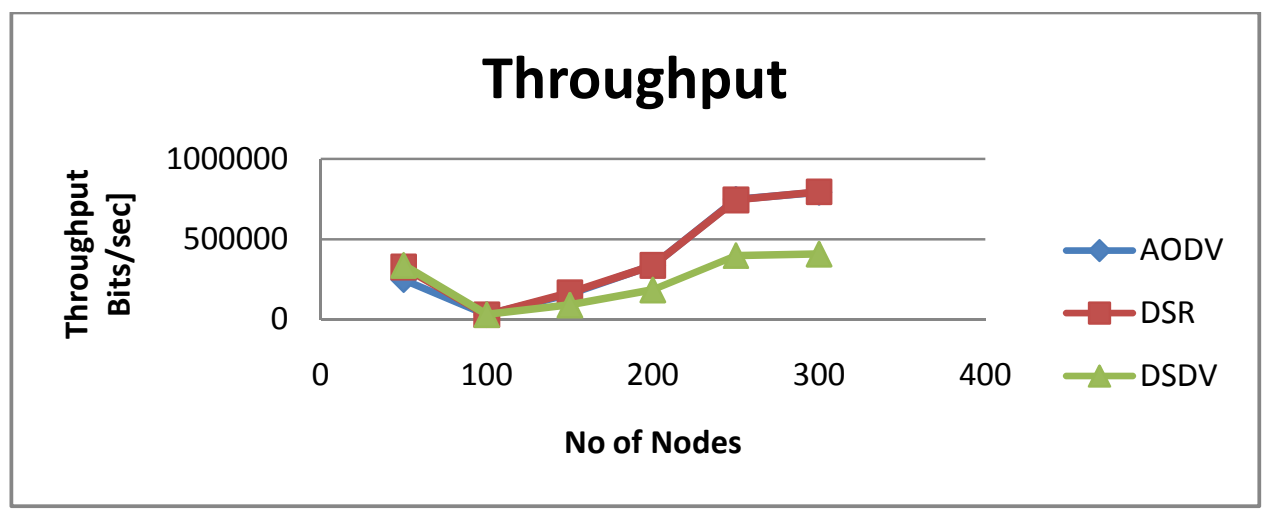

Figure: 11 Throughput vs Number of Nodes

Table 12: Readings Throughput vs No of nodes

\begin{tabular}{|c|c|c|c|}
\hline No. of Nodes & AODV & DSR & DSDV \\
\hline 50 & 250113 & 327655 & 337387 \\
\hline 100 & 32258.3 & 31485.7 & 32288 \\
\hline 150 & 161367 & 169092 & 91200 \\
\hline 200 & 337186 & 338347 & 185418 \\
\hline 250 & 747659 & 745504 & 397731 \\
\hline 300 & 791234 & 795437 & 407641 \\
\hline
\end{tabular}

\section{Packet Delivery Ratio :}

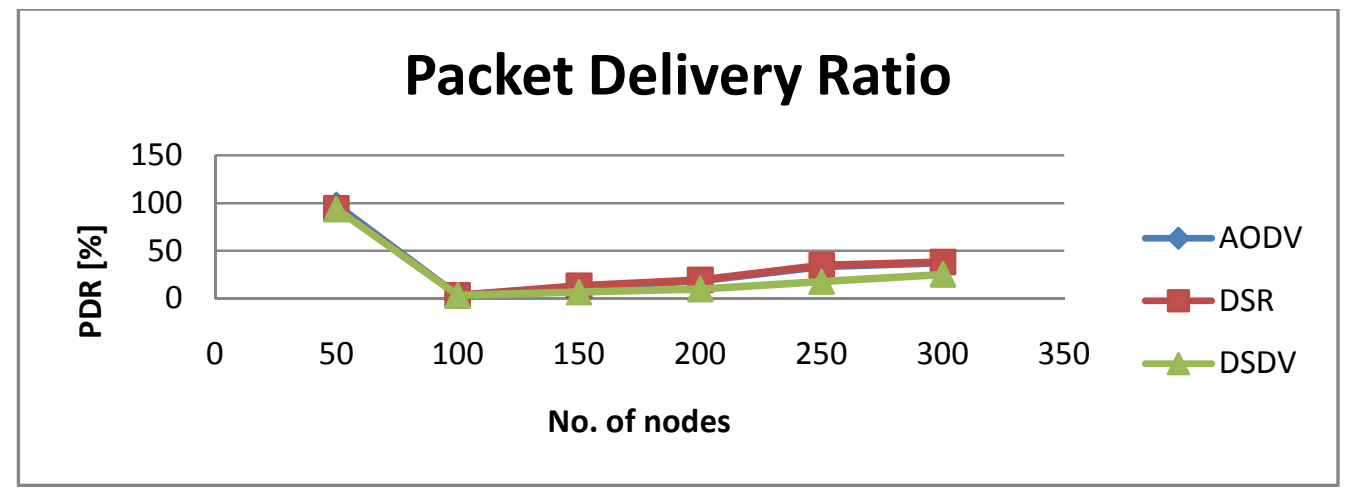

Figure: 12Packet Delivery Ratio vs Number of Nodes 
Emerging Trends in Electrical, Electronics \& Instrumentation Engineering: An international Journal (EEIEJ), Vol. 3, No. 1/2/3, August 2016

Table 13: Readings Packet Delivery Ratio vs No of nodes

\begin{tabular}{|c|c|c|c|}
\hline No. of Nodes & AODV & DSR & DSDV \\
\hline 50 & 97.9535 & 94.453 & 93.7094 \\
\hline 100 & 3.78286 & 3.78629 & 3.78629 \\
\hline 150 & 12.5855 & 13.6763 & 7.12701 \\
\hline 200 & 18.9219 & 19.7196 & 10.4143 \\
\hline 250 & 33.7407 & 34.8531 & 17.9539 \\
\hline 300 & 37.5425 & 38.5334 & 25.6532 \\
\hline
\end{tabular}

In Figure 12 we have observed a PDR has same up to 100 nodes and when the number of nodes has increased says 300 nodes in non-mobile networks then Packet delivery ratio for AODV is up to $95 \%$ to $100 \%$.Packet delivery ratio for DSR degrade up to $90 \%$ when node increases. Packet delivery ratio for DSDV is $40 \%$ to $60 \%$ and for varying nodes it degrades its performance up to $40 \%$. In Non-mobility scenario almost similar charachrastics showing in DSR and ADOV. DSR delivers packet up to $95 \%$ and DSDV delivers packet up to $30 \%$ and the AODV as well as DSR sent the number of packets in large network.

\section{Delay :}

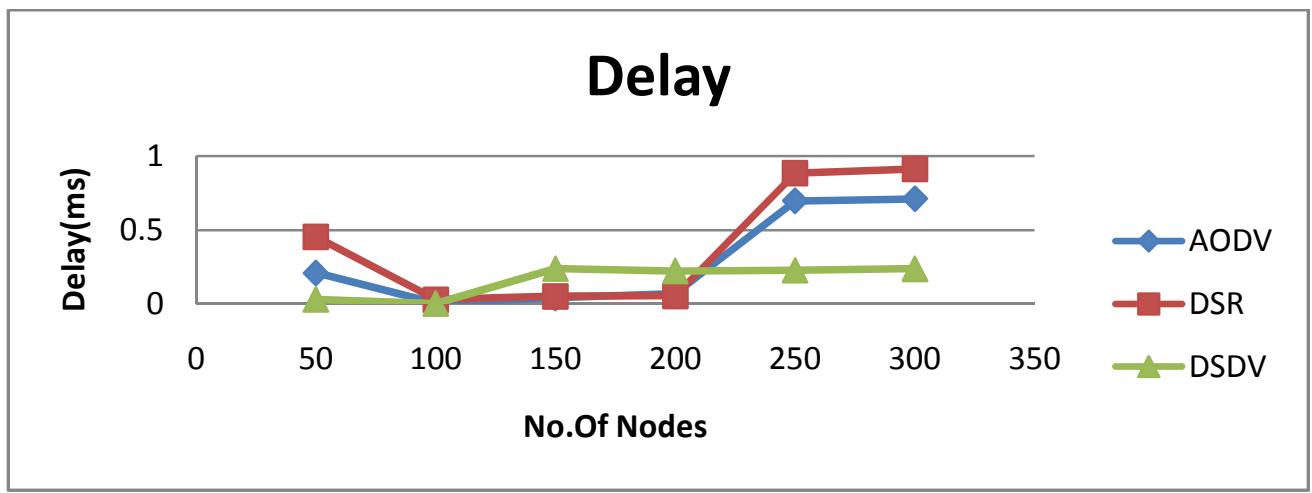

Figure: 13Delay vs Number of Nodes

Table 14: Readings Delay vs No of Nodes

\begin{tabular}{|c|c|c|c|}
\hline No. of Nodes & AODV & DSR & DSDV \\
\hline 50 & 0.208385 & 0.453372 & 0.0291946 \\
\hline 100 & 0.00346614 & 0.0286712 & 0.00235392 \\
\hline 150 & 0.0397165 & 0.051656 & 0.237831 \\
\hline 200 & 0.069358 & 0.0541943 & 0.222336 \\
\hline 250 & 0.695796 & 0.885329 & 0.22659 \\
\hline 300 & 0.70987 & 0.91234 & 0.23657 \\
\hline
\end{tabular}

In this section the figure 13 which shows that the delay is very high in DSR and average in AODV. DSR having high Delay where route is looked due to the route discovery mechanism However, the performance of AODV is very low due to increase a node says 300 and the DSR 
Emerging Trends in Electrical, Electronics \& Instrumentation Engineering: An international Journal (EEIEJ), Vol. 3, No. 1/2/3, August 2016

having more delay with respect to highest number of nodes. DSDV having very low delay in nonmobility which is easily maintained the sequence number as well as all the information should updated in routing table.

\section{Dropping Ratio :}

In figure 16 shows that all the protocols having average dropping ration which is above 100 nodes showing high constant dropping ratio in stable nodes. DSDV having constant packet dropping ratio from 100 to 300 nodes and when the increasing number of nodes says 100 nodes AODV and DSR comparatively lesser number of packet dropping ratio as compared with DSDV in nonmobility scenario. In RREP request the formation of routes in result the re-transmission which has resend the packets to destination. In large network DSR is very useful protocol in this section.

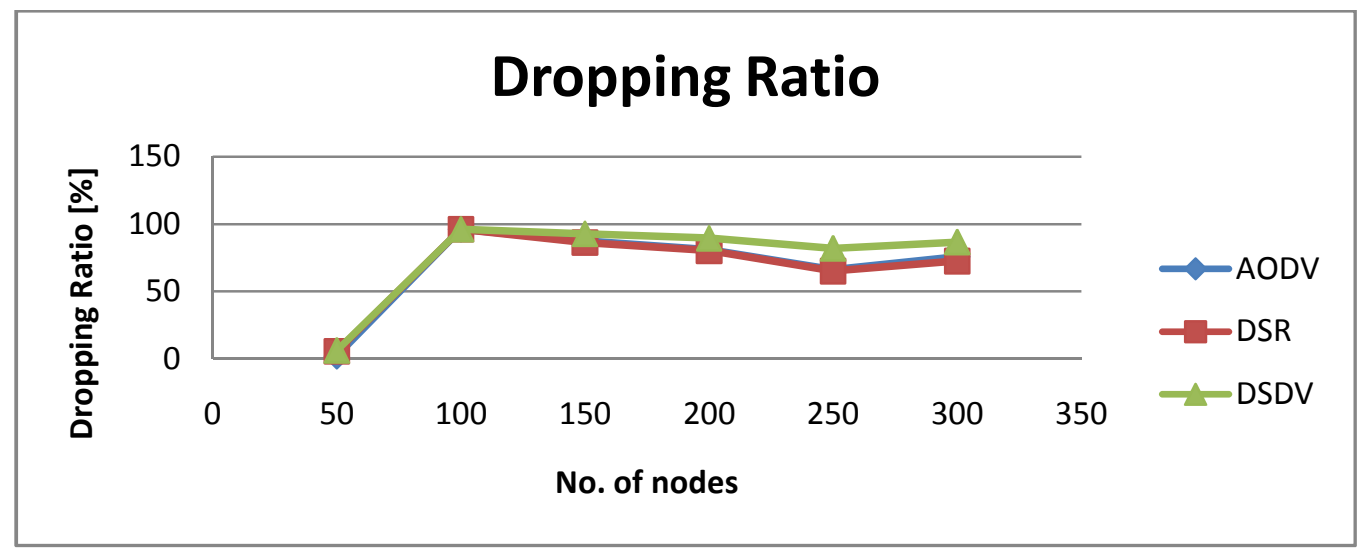

Figure: 16Packet Dropping Ratiovs Number of Nodes

Table 17: Readings Dropping Ratio vs No of Nodes

\begin{tabular}{|c|c|c|c|}
\hline No. of Nodes & AODV & DSR & DSDV \\
\hline 50 & 2.04651 & 5.54701 & 6.2906 \\
\hline 100 & 96.2171 & 96.2137 & 96.2137 \\
\hline 150 & 87.4145 & 86.3237 & 92.873 \\
\hline 200 & 81.0781 & 80.2804 & 89.5857 \\
\hline 250 & 66.2593 & 65.1469 & 82.0461 \\
\hline 300 & 75.7678 & 72.5443 & 86.7656 \\
\hline
\end{tabular}

\section{Average Energy Consumption :}

In this figure 17 shows the relationship between the number of nodes and the energy consumption. As per the reading DSDV having quite low energy consumption than AODV, but higher than DSR due charachrastics of DSDV protocols. This section graph look in like zigzag manner due to stable node unchanged their position in simulation so that route formation easily builds. 
Emerging Trends in Electrical, Electronics \& Instrumentation Engineering: An international Journal (EEIEJ), Vol. 3, No. 1/2/3, August 2016

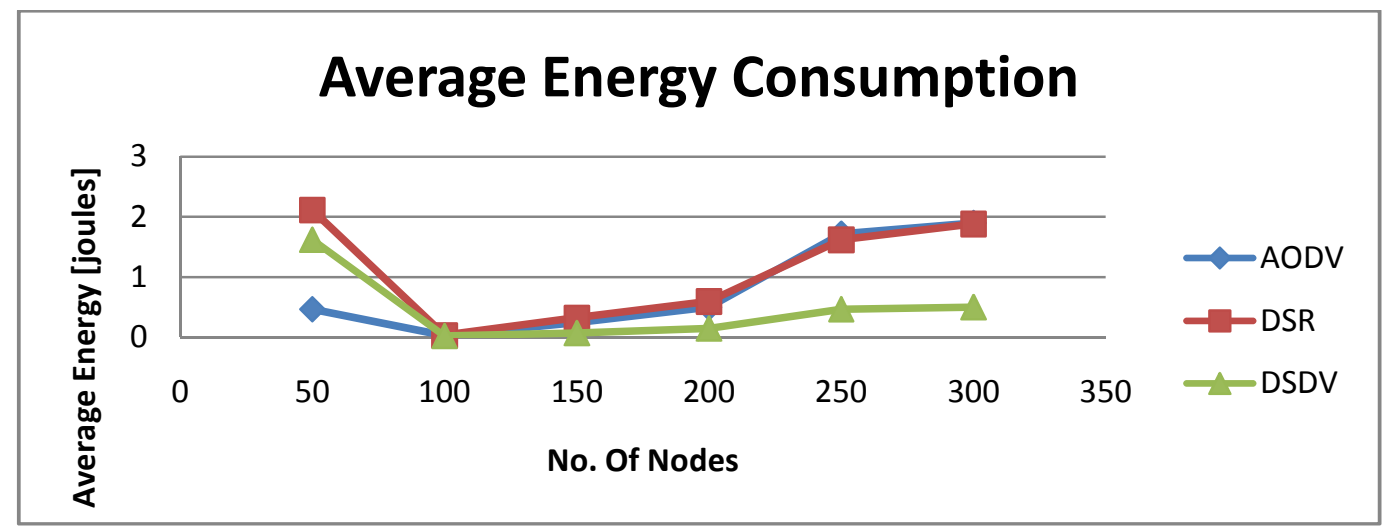

Figure: 17Average Energy Consumption vs Number of Nodes

Table 18: Readings Average Energy Consumption vs No of Nodes

\begin{tabular}{|c|c|c|c|}
\hline No of Nodes & AODV & DSR & DSDV \\
\hline 50 & 0.463298 & 2.10891 & 1.61724 \\
\hline 100 & 0.0297932 & 0.0306421 & 0.0194292 \\
\hline 150 & 0.240792 & 0.318992 & 0.0657646 \\
\hline 200 & 0.496486 & 0.592598 & 0.142517 \\
\hline 250 & 1.71636 & 1.61467 & 0.463413 \\
\hline 300 & 1.89655 & 1.87892 & 0.496541 \\
\hline
\end{tabular}

\section{CONCLUSION:}

This research paper evaluate that the three routing protocols namely AODV, DSR and DSDV and among that finding out best routing protocol for wireless networks. Every protocol have their own charachrastics.hence, this paper concludes that the AODV protocol perform well compared with DSR and DSDV protocols in less performance metrics. Reactive protocol uses the sequence number criteria which has uses the route maintenance. Proactive routing protocols are table driven. AODV uses routing tables,for determining freshness of routes in network simulation. On the other hand, DSR uses source routing which is work the basic work to send the packet to destination to large number of network congestion form.

1. AODV has the best all round performance. Need to improve the of DSR and DSDV performance. DSDV is good for the big mobile networks. The major benefit is tremendous support for multiple routes and multicasting.

2. From the Graphs that throughput for AODV is better than DSR routing protocol in mobility scenario (MANET) and almost same on stable node. DSDV having very low throughput then both AODV and DSR routing protocols.

1. Packet delivery ratio of DSDV is very good performance then AODV and DSR in both scenarios for up to 300 nodes. 
Emerging Trends in Electrical, Electronics \& Instrumentation Engineering: An international Journal (EEIEJ), Vol. 3, No. 1/2/3, August 2016

\section{REFERENCES:}

[1] A Quantitative Analysis and Behavioral Study of Routing Protocols in MANET " by Gyanendra Kumar Pallai , S Meenakshi, Amiya Kumar Rath, BansidharMajhi @ International Journal of Computer Science and Mobile Computing, Nov 2014.

[2] An Analysis of DSR, DSDV, AODV and Adv.-AODV Routing Protocols in MANET by Sandeep Gautam, Shashank dwivedi, IJRITCC, August 2015.

[3] Applications of MANET Routing Protocols in Sensor Network by Venetis Kanakaris, David Ndzi, and Kyriakos Ovaliadis, (IJRRAN), December 2011.

[4] Assessment Of Throughput Performance Under NS2 In Mobile Ad Hoc Networks (MANETs)" by Liliana EncisoQuispe and Luis Mengual Galan, 2013 Fifth International Conference on Computational Intelligence, Communication Systems and Networks.

[5] Comparison Estimation of Various Routing Protocol in Mobile Ad-hoc Network by V. V. Mandhare and R. C. Thool, (C) 2015, IJARCSSE.

[6] Competitive study of Ad hoc Routing protocol AODV,DSR,DSDV in Mobile Adhoc network" by Pranav kumarsingh, Dipankar Sutradhar, Journal ISSN.

[7] Comparison of MANET Routing Protocols in Different Traffic and Mobility Models by Sabina Barakovi, SuadKasapovi and JasminaBarakovi, Telfor Journal,2011.

[8] Evaluation of AODV, DSR and DSDV Routing Protocols for Static WSNs: ASimulation Study by Ali A.S. Ihbeel, HaseinIssaSigiuk, Journal of Networking Technology ,August 2012.

[9] NETWORK SIMULATORS FOR NEXT GENERATION NETWORKS: AN OVERVIEW by Monika ,Akhil Kaushik and Mani Shekhar, IJMNCT, 2014.

[10] PERFORMANCE ANALYSIS OF AODV, DSR AND DSDV ROUTING PROTOCOLS IN MOBILE AD-HOC NETWORK (MANET) by PARUL SHARMA, ARVIND KALIA AND JAWAHAR THAKUR, ISSN: 0976-8742, February 15, 2012

[11] PERFORMANCE COMPARISON OF MOBILE AD HOC NETWORK ROUTING PROTOCOLS By Mandeep Kaur Gulati and Krishan Kumar, IJCNC, March 2014.

[12] PERFORMANCE ANALYSIS OF AODV, DSDV AND DSR IN MANETS “ byAkshai Aggarwal, Savita Gandhi, Nirbhay Chaubey, IJDPS, November 2011.

[13] Performance Comparison and Improvement of Routing Protocol-DSR" Nitin Tyagi : G.L.A.I.T.M, Mathura

[14] Performance comparison of AODV,DSR and LAR1in Mobile Ad hoc network on simulation Time" by Rajeev Paulus, tanbeerkaur, reema Garg, journal,IOSR-JECE,Oct@ 2013.

[15] Performance comparison of routing protocols in MANET by P.Manickam, t.gurubasker,IJWMN,journal, feb 2011.

[16] Performance study of Broadcast based Mobile Adhoc Routing Protocols AODV, DSR and DYMO" by Parma Nand, Dr. S.C. Sharma, International Journal of Security and Its Applications, January, 2011, IIT Roorkee, INDIA.

[17] Performance comparison of AODV, DSDV, DSR routing protocols in MANET" by Preetigaharwar, Sunil gupta,research paper,IJARCSSE@2013.

[18] Performance Evaluation of AODV, DSDV and DSR Routing Protocols Using NS-2 Simulator" byNehalJadeja, Roma Patel, IJERA, March -April 2013.

[19] PERFORMANCE INVESTIGATION OF ROUTING PROTOCOLS OF MOBILE AD-HOC NETWORKS USING CBR AND TCP TRAFFIC, Samayveer Singh, A K Chauhan and AvinashSoam, JGRCS, June 2011.

[20] Performance Analysis and Comparison of MANET routing Protocols by Kuljit Kaur, Swati Jindal, Lavneet Bansal, IJCSIT, 2011.

[21] Simulating Sensor Networks in NS-2by IAN T. DOWNARD, May 31, 2004.

[22] The effect of velocity of nodes on the performance of routing protocols in MANET" by ZubairIqbal,Prachigupta, journal,IJCA,july@2013. 
Emerging Trends in Electrical, Electronics \& Instrumentation Engineering: An international Journal (EEIEJ), Vol. 3, No. 1/2/3, August 2016

[23] Traffic Pattern Based Performance Comparison of AODV, DSDV \& OLSR MANET Routing Protocols using Freeway Mobility Model by Suman Kumari, Sunil Maakar ,Suresh Kumar, R K Rathy, IJCSIT, 2011.

[24] Varying Pause Time Effect on AODV, DSR and DSDV Performance, by Zafar Mahmood, Muhammad Awais Nawaz, DrMudassar Iqbal, Saleem Khan, Zia ulHaq, ijwmt, March 2015.

\section{AUTHORS}

Paresh Acharekar is working as Software consultant in Atos Origin India Private Limited, Pune, and India.my research focus on routing protocols in MANET Mobility as well as Non-Mobility scenarios.

Dr. Saurabh Mehta is Professor and Head Department of EXTC, VIT Engineering College Mumbai, India and his area of specializations includes a core wireless network, Sensor Network. His wireless and NS2 ideas helps me lot in this research paper.

Prof. Shraddha Panbude is working in VIT Engineering College Mumbai, India and she is my guide of Master's project.
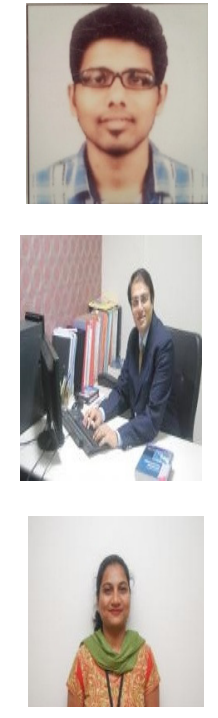